\title{
A WAX SEAL METHOD FOR DETERMINING THE LOWER LIMIT OF AVAILABLE SOIL MOISTURE ${ }^{\mathrm{I}}$
}

\author{
Lyman J. Briggand H. L. Shantz
}

(WITH TWO FIGURES)

All soils upon which the plant cover has wilted through lack of water will still be found to contain moisture, varying in amount from less than I per cent in a coarse sand to 25 per cent or more in the heaviest clay soils. It is therefore highly important in all studies of the relationship of soil moisture to plant growth to recognize clearly that a simple statement of the moisture content of the soil gives no indication whatever of the amount of water actually available to the plant. To ascertain the amount of available soil moisture, it is necessary to determine the actual water content of the soil, and in addition the minimum to which the plant can reduce the soil moisture content. The difference between these two determinations represents the soil moisture that is actually available to the plant. The minimum to which a plant can reduce the water content of a soil is dependent upon a number of variable factors, and is somewhat lower than the moisture content corresponding to the wilting point. Practically speaking, the permanent wilting of the plant marks the cessation of growth, and in accordance with previous usage has been considered in the present paper as the criterion of non-availability. In a subsequent paper, we propose to compare the minimum of available moisture, as determined by the wilting point and by the death point, and to show to what extent this determination is affected by varying conditions of temperature, humidity, and light.

The method which we have employed consists essentially (I) in the use of an impervious pot, (2) in sealing over the soil surface in the pot with wax so as to prevent all evaporation from the soil, and (3) in keeping the soil mass at approximately constant temperature. Under these conditions the water remaining in the soil at the time of wilting is non-available to the plant.

${ }^{I}$ Published with the permission of the Secretary of Agriculture.

Botanical Gazette, vol. 5I]

[2 I 0 


\section{Essentials in determining non-available moisture}

In determining the non-available moisture content of a soil, we have found that the following precautions are necessary:

I. The soil mass should be as uniform as possible, since the nonavailable moisture varies with the texture of the soil, and is consequently affected by stratification or other non-uniformity of the soil mass.

2. The soil should be brought to a uniform moisture content before being placed in the pots. Otherwise, small volumes of soil may remain dry and thus introduce an error in the final moisture determinations.

3. All loss of water from the soil should be prevented except that resulting from the transpiration of the plant. Otherwise, the surface soil may dry out below the minimum limit of available moisture, before the inner soil mass has reached this limit.

4. All sudden fluctuations in temperature must be avoided. Otherwise, condensation will occur on the inner walls of the pot as the result of distillation from the soil, due to the difference of temperature. This condensed water will be absorbed by the roots in contact with the inner walls of the pot, and the moisture content of the principal soil mass may thus be reduced below the minimum of available soil moisture.

\section{Description of the method}

In working out a practical method embodying the above requirements, which have not been fully complied with in the methods heretofore described, we have adopted the following procedure:

I. The air-dried soil is sifted through a $2 \mathrm{~mm}$. screen to remove gravel and to insure greater uniformity: The soil, after sifting, is thoroughly mixed, special care being taken to avoid the separation of the fine and coarse particles. Variation in the amount of gravel and coarse sand in the different pots produces irregularities in the non-available moisture determinations, due to the fact that the coarse particles add to the weight of the soil without appreciably contributing to its water-holding properties.

In certain soils, notably those deficient in lime, it is best to add a small amount of calcium carbonate to the soil before planting, to insure the growth of the seeds. 
2. The proper amount of water to be added to the air-dried soil is dependent upon the soil texture, varying from 5 per cent for sand to 30 per cent for clay. The amount to be used is best determined by adding water slowly from a graduate to a small weighed portion of soil until a condition of good tilth is reached. A heavy soil can be moistened without puddling by placing it on a slab or table in a cone-shaped pile, with a large crater in the top, into which the required amount of water is slowly poured. The crater is then filled with dry soil from the sides, and the whole mass is covered to prevent evaporation, and allowed to stand over night, or preferably longer. The soil is then thoroughly mixed, during which process it is sifted through a coarse screen ( $\frac{1}{4}$ inch mesh). Any pellets of soil having more than their proportionate amount of water will be removed in this way. After mixing, the moist soil should be kept in a tight receptacle until ready for use.

Impervious pots of course must be used in order to prevent the soil in contact with the pots from drying out below the minimum of available soil moisture. We have found that ordinary straightwalled drinking glasses form very satisfactory pots for this work. During the process of filling the glasses, the soil is slightly compacted by jarring the bottom of the glass against the hand. Three to five seeds are planted in each pot, about $\mathrm{I} \mathrm{cm}$. in depth, after which the surface is smoothed and compacted slightly. The soil surface after planting should be about $\mathrm{I} \mathrm{cm}$. below the edge of the glass. It is sometimes advantageous to plant seeds which have just begun to germinate; this insures a uniform stand, and avoids excessive respiration below the wax seal.

3. In sealing the pots the wax is heated slightly above the melting point, and a sufficient amount is poured into the pot to cover the soil surface about $3 \mathrm{~mm}$. in depth. The pot is rocked slightly so as to bring the wax into thorough contact with the inner walls of the pot, after which the excess wax is poured off. If the wax is at the proper temperature, this will give a perfect uniform seal over the entire surface. If the seal is not perfect, the process is repeated. The wax layer should be approximately I mm. in thickness, and should be in close contact with the soil. If the wax does not adhere to the soil surface, the pots should be resealed, since the plants may buckle under the wax cover if it is not adherent. 
In the case of monocotyledons, we have found that the wax seal can best be added immediately after planting the seeds. On germination, these plants will grow readily through the wax, which forms a perfect seal around the stems (fig. I). With dicotyledons it is advisable to keep the pots in a moist chamber, to reduce evaporation until the seedlings appear above the ground, when the wax seal can be applied without injury to the plants.

Even in the case of dicotyledons, this wax seal is often applied at the time of planting. This prevents the soil from drying out between the time of planting and complete germination. Plants which do not raise the cotyledons above the soil surface and those with very small seeds often push through the wax without breaking the seal. Other dicotyledons push their way through the wax cover without any difficulty, although it is necessary to reseal these pots after the seedlings are all up, especially in the case of plants with large cotyledons, such as the bean, squash, cucumber, etc.

Aeration, when necessary, can readily be accomplished by making two small holes through the wax to the bottom of the pot on opposite sides. A glass tube drawn to

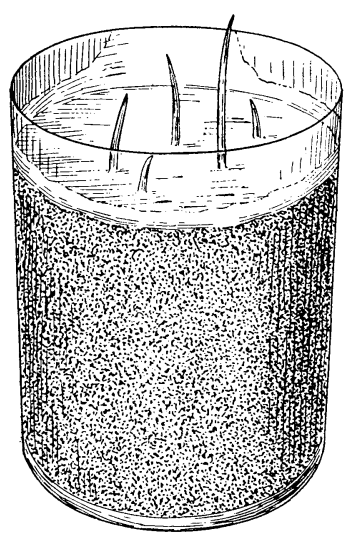

FIG. I.-Showing the wax seal on the surface of the soil in the glass container with wheat seedlings growing through the seal; the wax was applied immediately after planting the seeds. a small opening and connected with a wash bottle is forced into one hole to supply moist air, and a similar glass tube is forced into the opposite opening and attached to an aspirator to withdraw the air from the pot. The wax forms a perfect seal around the glass tubes. In this way many pots can be aerated and the holes resealed with a hot wire in a comparatively short time.

The wax seal method is also particularly adapted to the study of transpiration, since all loss of water is avoided except through the plant tissues.

4. Serious fluctuations in temperature can be avoided by immersing the pots to within $5 \mathrm{~mm}$. of the top in a tank, preferably one through which a small stream of tap water is constantly flowing. 
In case this is not feasible, the pots can be immersed in a barrel or large tank of water, in which a constant circulation is maintained.

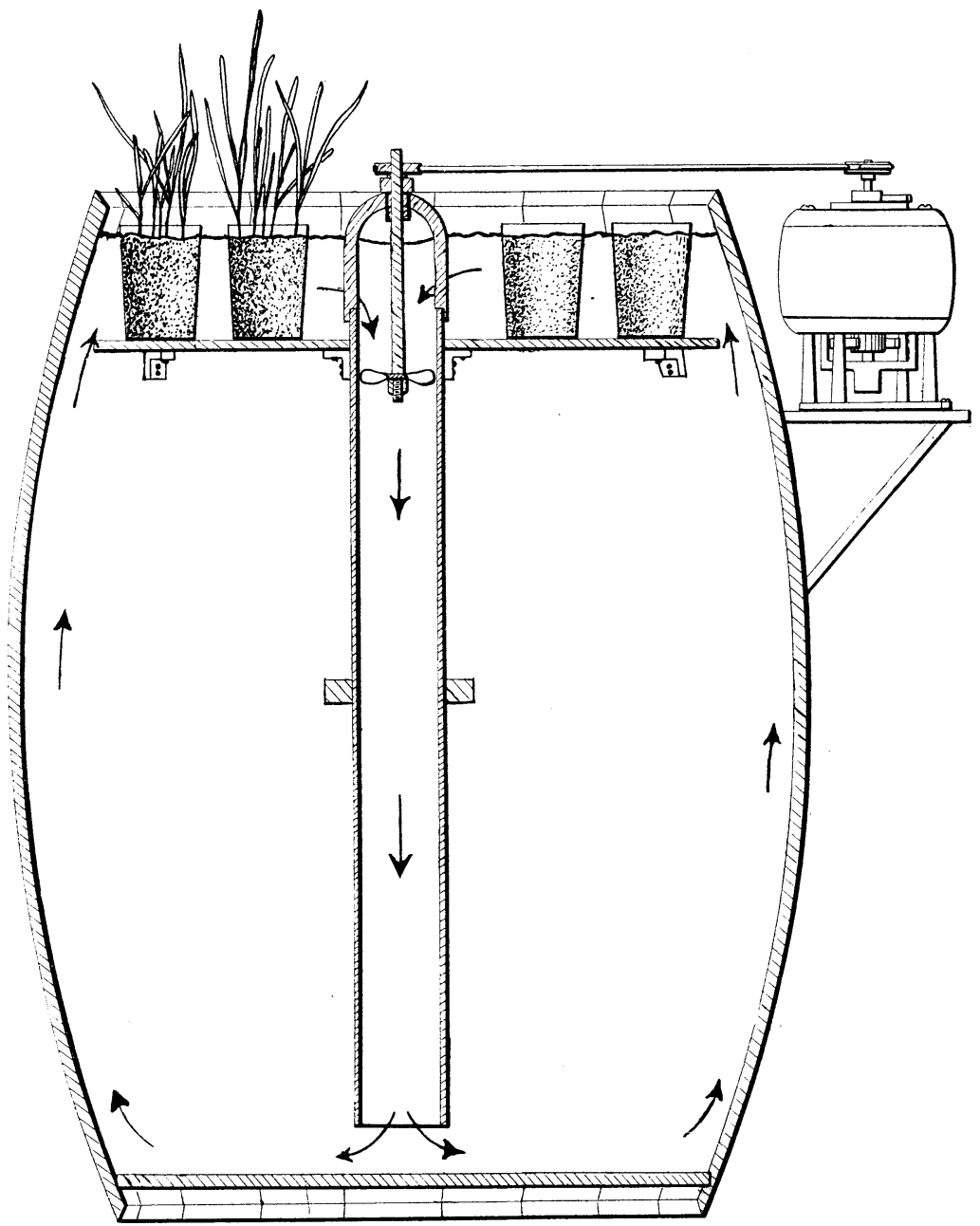

FIG. 2.- Showing tank for preventing sudden changes in the temperature of the soil used in non-available determinations; the propeller in the central tube causes a constant circulation of the water around the pots.

The most satisfactory form of stirring device that we have used consists of a small propeller in a tube (fig. 2). The upper end of the tube carries a yoke which supports the bearing of the propeller 
shaft. The propeller is driven by a horizontal belt from a small vertical shaft motor mounted on a bracket at the top of the barrel. The lower end of the propeller tube extends nearly to the bottom of the barrel, while the upper end fits into the center of the solid shelf on which the pots rest. An annular space is provided between the shelf and the barrel. The operation of the stirrer causes a circulation downward through the central tube, upward along the walls of the barrel, and radially inward across the shelf and around the pots. While the temperature of even this large volume of water will vary somewhat during the day, these changes are very gradual, and are found to produce no detrimental effect. For the purpose, a simple arrangement of this kind is preferable to a more elaborate thermostat.

As soon as the plants in a pot show unmistakable signs of wilting, the water content of the soil is determined. The pot is inverted, and the soil mass removed intact by gently jarring the edge of the pot against the bench in the usual way. The lower two-thirds of the soil mass is taken for the moisture determination, since the roots do not usually develop so extensively in the upper portion. The moisture determination is based upon the loss of water taking place when the soil is dried to constant weight at $100^{\circ} \mathrm{C}$., the percentage of moisture being based upon the dry weight of the soil.

\section{Composition of the wax seal}

For sealing the pots, we have tried paraffin, petrolatum, beeswax, and tallow in various proportions. Of these, we have found a wax composed of 80 per cent paraffin (melting point $45^{\circ} \mathrm{C}$.) and 20 per cent petrolatum to be most satisfactory for use at ordinary temperatures, exact proportions not being important. This mixture melts at so low a temperature and has such low heat conductivity that it can be poured into a pot around the most delicate seedling without injury. This is an important point in the case of delicate dicotyledons. On cooling, this wax adheres well to the glass and to the soil, forming a perfect seal. Other mixtures, notably those containing beeswax, show a decided tendency to separate from the glass on cooling, necessitating resealing the edges with a hot iron. 
None of the substances mentioned give good results when used alone. Paraffin $\left(45^{\circ}\right)$ stretches, petrolatum creeps, and beeswax, tallow, and the higher paraffins crack. Except in the case of the soft paraffin, which stretches, the plants show no difficulty in penetrating the wax cover, even when a wax as hard as that used in making the ordinary commercial phonograph records is used as a seal.

During the winter in the greenhouse the paraffin-petrolatum mixture gives excellent results even when left in direct sunlight. However, during the warm portion of the year direct sunlight is likely to melt this wax, and in this way break the seal and cause damage to the plants, due to the wax creeping over the plant surface. The beeswax mixtures have proven best during warm weather. A mixture of 10-30 per cent beef tallow with beeswax, or of 8-r 2 per cent of petrolatum with beeswax, has proven an excellent material both in greenhouse and for out-of-door work.

Modelling clay has also been used to seal the pots, but it is not so easily applied as the wax, and is not suitable for use with delicate seedlings.

\section{Experimental error}

In determining the non-available moisture in a given soil, some variation will be found in the results obtained from the individual pots. This variation is probably due in part to the lack of uniformity of the soil in the different pots, but mainly to the fact that in some pots the roots are distributed through the soil mass much more uniformly than in others. When the root distribution is defective, the mean distance through which the soil moisture must move through capillary action is relatively greater. Since capillary movement is very slow in soils that are approaching their non-available moisture content, the portion of the soil not penetrated by roots would have a somewhat higher moisture content. The non-available moisture determination in the case of an imperfect root distribution would consequently be somewhat too high. On the other hand, errors arising from the distillation of water to the walls of the pot would result in giving a non-available determination below the true value.

Some uncertainty also arises in connection with the determina- 
tion of the wilting point. Plants often wilt down during the day and recover during the night. The wilting of a plant in the hot part of the day is therefore no indication that moisture is not available. We have consequently considered a wilted condition in the morning as proof that the moisture content had been reduced to the point of non-availability. Check determinations were repeat-

TABLE I

INDIVIDUAL POT MEASUREMENTS OF NON-AVAILABLE MOISTURE FOR KUBANKA WHEAT IN THREE SOIL TYPES

\begin{tabular}{|c|c|c|c|}
\hline & $\begin{array}{l}\text { Fine sand } \\
\text { per cent }\end{array}$ & $\begin{array}{l}\text { Fine sandy loam } \\
\text { per cent }\end{array}$ & $\begin{array}{l}\text { Clay loam } \\
\text { per cent }\end{array}$ \\
\hline & $\begin{array}{l}2.6 \\
2.1 \\
2.7 \\
2.8 \\
2.6 \\
2.7 \\
2.7 \\
2.6 \\
2.5 \\
2.6 \\
2.4 \\
2.7 \\
2.6 \\
2.5 \\
2.7 \\
2.7\end{array}$ & $\begin{array}{r}\ldots \\
\ldots \\
\ldots \\
9.7 \\
9.3 \\
9.9 \\
\text { rO.I } \\
9.7 \\
9.4 \\
9.6 \\
9.3 \\
9.4 \\
9.8 \\
9.3 \\
9.7 \\
9.4\end{array}$ & $\begin{array}{l}\text { I6.9 } \\
\text { I6.8 } \\
\text { I6.4 } \\
\text { I6.2 } \\
\text { I5.5 } \\
\text { I } 5.7 \\
\text { I } 7.3 \\
\text { I6.7 } \\
\text { I5 } 5.6 \\
\text { I6.0 } \\
\text { I6.0 } \\
\text { I6.2 } \\
\text { I6.3 } \\
\text { I6.3 } \\
\text { I6.7 } \\
\text { I6.3 }\end{array}$ \\
\hline 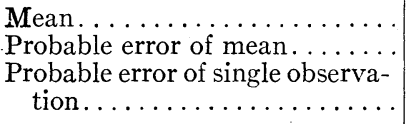 & $\begin{array}{r}2.59 \\
\pm 0.0 .3 \\
\pm 0 . \mathrm{II}\end{array}$ & $\begin{array}{r}9.66 \\
\pm 0.05 \\
\pm 0.18\end{array}$ & $\begin{array}{l}16.3 \\
\pm 0.09 \\
\pm 0.34\end{array}$ \\
\hline
\end{tabular}

edly made by placing the pots containing wilted plants under a bell jar in nearly saturated air. These plants were unable to recover their turgidity. Since the wilting point is influenced to some extent by the temperature and humidity of the air of the plant house, these conditions should be determined and kept as uniform as possible during the growth of the plants.

The degree of accuracy which may reasonably be expected by the wax seal method is shown by the series of determinations made with Kubanka wheat shown in table I, which gives the percentage of non-available moisture found in each pot for three types of soil. The plants were grown in an ordinary plant house. The average temperature was about $70^{\circ} \mathrm{F}$, and the relative humidity 
about 85 per cent. The mechanical composition of the soils employed is shown in table II.

Table I shows the arithmetical mean of each series of determinations, together with the probable error of the mean and the probable error of a single observation. The term "probable error" is used in its usual mathematical sense, that is to say, in the case of the series of determinations in sand, the chances are even if the series were repeated with the same soil that the mean would lie between the values 2.56 and 2.62 ; and if the experiment were repeated with a single pot, the chances are even that the non-available moisture in this pot would fall between 2.48 and 2.70 . The prob-

TABLE II

Mechanical analyses of soll samples used in the Determinations given in TABLE I*

\begin{tabular}{|c|c|c|c|c|c|c|c|}
\hline & $\begin{array}{c}\text { Fine } \\
\text { gravel } \\
2-\text { I mm. }\end{array}$ & $\begin{array}{c}\text { Coarse } \\
\text { sand } \\
I-0.5 \mathrm{~mm} .\end{array}$ & $\begin{array}{l}\text { Medium } \\
\text { sand } \\
0.5^{-} \\
0.25 \mathrm{~mm} .\end{array}$ & $\begin{array}{c}\text { Fine } \\
\text { sand } \\
0.25^{-} \\
0.1 \mathrm{~mm} \text {. }\end{array}$ & $\begin{array}{l}\text { Very fine } \\
\text { sand } \\
0 . \mathrm{I}^{-} \\
0.05 \mathrm{~mm} .\end{array}$ & $\begin{array}{c}\text { Silt } \\
0.05^{-} \\
0.005 \mathrm{~mm}\end{array}$ & $\begin{array}{c}\text { Clay } \\
0.005^{-} \\
0 \mathrm{~mm} \text {. }\end{array}$ \\
\hline & per cent & per cent & per cent & per cent & per cent & per cent & per cent \\
\hline $\begin{array}{l}\text { Fine sand } \ldots . . . \\
\text { Fine sandy loam }\end{array}$ & $\begin{array}{l}0.4 \\
0 . I\end{array}$ & $\begin{array}{l}9.8 \\
\text { I. } 5\end{array}$ & $\begin{array}{r}\text { I } 7.0 \\
\text { I. } 2\end{array}$ & $\begin{array}{l}50.1 \\
\text { IO. } 2\end{array}$ & $\begin{array}{l}14 \cdot 3 \\
40.6\end{array}$ & $\begin{array}{r}4 \cdot 7 \\
30.2\end{array}$ & $\begin{array}{l}3 \cdot 9 \\
6.0\end{array}$ \\
\hline Clay loam..... & $0 . I$ & $2 \cdot 3$ & 2.0 & 6.6 & I3.9 & 52.6 & 22.0 \\
\hline
\end{tabular}

* Mechanical analyses made by the Bureau of Soils.

able error of the mean is about 0.005 , and that of the single observation 0.02 of the actual non-available determination in the loam and clay soils, while the corresponding probable error is about twice as great in sand. It appears, therefore, that while there is considerable variation in individual pots, the mean of a suitable series represents the non-available moisture content of a given soil with an accuracy fully comparable with the accuracy with which the soil itself can be defined through its physical properties.

\section{Summary}

All soils upon which the plant cover has wilted through lack of water will still be found to contain moisture, varying in amount from less than I per cent in coarse sands to 25 per cent in the heaviest clays, and even more in the peat soils. The available water in the soil at any time is represented by the difference between the actual water and the non-available portion. It is consequently 
essential in any critical study of the relation of plant growth to soil moisture to be able to determine for any soil the maximum amount of non-available moisture.

In determining the non-available moisture, the permanent wilting of the plant has been taken as the criterion of non-availability. In making such determinations the following precautions are necessary:

I. The soil used should be as uniform as possible.

2. The soil should be brought to a uniform water content before being used.

3. All loss of water should be prevented except that due to the transpiration of the plant.

4. All sudden fluctuations in soil temperature should be avoided.

5. It should be definitely ascertained that the plant cannot recover turgidity without additional moisture being supplied.

The method which we have employed consists in growing the plants in a small glass pot, evaporation from the soil surface being prevented by means of a seal of wax which is melted and flowed over the soil surface. In the case of monocotyledons, this wax seal can be applied immediately after planting the seeds, and the seedlings will grow readily through the wax, forming a perfect seal around the stems. In the case of dicotyledons, the wax, which is usually a mixture of paraffin and vaseline having a low melting point and low heat conductivity, can be melted and flowed around the stems of the seedlings without injury. During growth, the pots are kept immersed in a water bath to avoid condensation of the soil moisture on the pot walls.

The probable error of the mean of the determinations from I2 pots or more does not usually exceed $\circ$ I per cent of actual soil moisture, which is fully comparable to the accuracy with which the soil itself can be defined through its physical properties.

The wax seal method is also particularly adapted to the study of transpiration, since all loss of water is avoided except that taking place through the plant.

Bureau of Plant Industry

Washington, D.C. 